\title{
Regulation and Efficiency Incentives: Evidence from the England and Wales Water and Sewerage Industry
}

\author{
FABRIZIO ERBETTA * \\ University of Piemonte Orientale, Faculty of Economics \\ HERMES, Centre for Research on Regulated Services
}

MARTIN CAVE

Warwick Business School, University of Warwick

\begin{abstract}
This paper evaluates the impact of the tightening in price cap by OFWAT and of other operational factors on the efficiency of water and sewerage companies in England and Wales using a mixture of data envelopment analysis and stochastic frontier analysis. Previous empirical results suggest that the regulatory system introduced at privatization was lax. The 1999 price review signaled a tightening in regulation which is shown to have led to a significant reduction in technical inefficiency. The new economic environment set by price-cap regulation acted to bring inputs closer to their cost-minimizing levels from both a technical and allocative perspective.
\end{abstract}

\section{Introduction}

The England and Wales water and sewerage industry was privatized in 1989 and thenceforth has been subject to a sequence of five-year price controls in the form of price caps. Price-cap regulation is set out to be a high-powered incentive scheme. However, previous empirical findings have shown that the cap introduced at privatization in 1989 had been lax (Saal and Parker, 2000), in the sense of allowing real price increases and the evidence that the first price review in 1994 produced efficiency gains is weak (Saal and Parker, 2001 and 2004). This may be explained by the double duty of the regulator to encourage a higher level of efficiency and provide the companies with the financial resources to support their investment programs.

The 1999 price review signaled a change in the implementation of regulatory policy by imposing for the first time a real price reduction.

\footnotetext{
* Contact Author. Faculty of Economics, University of Piemonte Orientale, Via Perrone 18, 28100 Novara, Italy, Tel +39 (0)321375.440, Fax +39 (0)321 375405, Email: fabrizio.erbetta@eco.unipmn.it. We appreciated the useful comments from Ian Byatt, Giovanni Fraquelli, Mark Stewart and seminar participants at OFWAT, although of course we are solely responsible for any errors.
} 
As noted by Weyman-Jones et al (2006), incentive regulation has many attractive properties but a number of practical concerns may arise when a regulation model has to be implemented in practice. Therefore, it appears that the attainability of many of the desirable properties of incentive regulation is an empirical issue (Uri, 2003).

Our paper aims at exploring whether incentive regulation (namely, the tightening of regulation in 1999) actually resulted in an increase in performance. In particular, issues we wish to deal with - and that may be of interest to regulators in a broader perspective - are: how is it possible to account for different environmental conditions when implementing a yardstick competition model? Is incentive regulation able to drive to improved efficiency under both a technical and allocative perspective? Does incentive regulation (and other environmental variables) differently impact on the efficient use of individual inputs?

In facing these questions, we used a DEA-based two stage approach derived from Fried et al (2002). In the first stage, DEA (Data Envelopment Analysis) is run over a balanced panel data of the ten water and sewerage companies for the period from 1992-93 to 200405. In this stage, estimates of technical and allocative efficiency are obtained. In the second stage, we calculate input-specific excess utilization and allocative distortion measures, and regress them on a set of environmental variables using Stochastic Frontier Approach (SFA). These explanatory variables are chosen to represent both the operational and regulatory environment under which the firms operate. In this way, we provide a decomposition of the DEA-based overall technical and allocative inefficiency into three components: environmental impact, pure managerial inefficiency and statistical noise.

This approach has several advantages, which may be regarded as attractive properties by regulators. First, it makes it possible to incorporate environmental effects and statistical noise into a DEA-based model. Second, it allows us to evaluate the impact of operational and regulatory environment on both technical and allocative efficiency of regulated firms. Third, it provides input-specific efficiency measures, which can be decomposed in order to identify the pure managerial efficiency separately from environmental effects and noise.

The remainder of the paper is organized as follows. Section 2 provides a general description of the regulatory regime for the English and Welsh water and sewerage industry, which offers a context to the research question this paper deals with. Section 3 is a review of the existing literature dealing with efficiency in the water industry in England and Wales as well as abroad. The model specification is set out in section 4 . Section 5 focuses on the input and output variables along with the arguments that support their choice, while section 6 specifies the environmental and regulatory factors. Empirical results are presented and discussed in section 7. Section 8 concludes and briefly notes some policy implications.

\section{Regulation of the water industry}

At the privatization of the industry in 1989, the ten Regional Water Authorities (RWA) were transferred to the private sector with the functions of water supply, sewerage collection and sewage disposal, and they became Water and Sewerage Companies (WaSCs). The responsibility for drinking quality and environment regulation was passed to independent agencies, respectively, the Drinking Water Inspectorate (DWI) and the National Rivers Authority, the latter absorbed into the Environment Agency (EA) in 1996. The then current integrated structure of the water and sewerage industry was thus almost 
entirely preserved, with the exception of quality regulation functions which were considered more opportunely managed by public agencies (Hunt and Lynk, 1995).

These ten privatized companies, along with the 29 already privately-owned water only companies, formed the England and Wales water and sewerage industry. The industry structure is concentrated, with the ten WaSCs providing both water and sewerage services in England and Wales, and accounting for $78 \%$ in terms of water supplied to the population and $85 \%$ in terms of served area (Saal and Parker, 2000). Given the large amount of the assets transferred to the private sector, and the (then) monopolistic nature of the established companies, the function of regulating prices was given to an independent agency, the Office of Water Services (OFWAT), whose main task is to set price in a way that encourages the companies to generate investment funds, enhance their efficiency level and fulfill programs for achieving high quality and environmental standards.

Since privatization in 1989, the England and Wales water and sewerage industry has been subject to a regulatory regime based on price-cap regulation. This is a substitute for competition and is implemented by allowing companies to change prices according to the inflation rate (RPI, Retail Price Index), plus or minus a $K$ factor decided by the regulator (OFWAT). ${ }^{1}$ This factor is composed of a negative component that accounts for the potential increase in efficiency that the regulator judges to be achievable ( $X$-efficiency) and a positive component that is set to accommodate the large capital investment program of the companies. The price determinations are also based on a comparative performance assessment (yardstick competition). This system allows the regulator partially to circumvent the lack of information that typically characterizes the relationship between regulator and regulatees. Once prices are set, if firms manage to deliver service at a lower average cost than that assumed by the regulator, they keep the resulting benefits. The regulator can thus provide firms with the incentive to increase their efficiency and then return part of the realized cost savings to the customers through a subsequent reduction in prices. Price cap regulation is regarded as a higher-powered incentive scheme than rate of return regulation. The attempt to increase efficiency should lead to a reduction in the use of the resources to produce a specified output (that is, increased technical efficiency), and/or to a change in input mix, given the relative input prices, in order to minimize overall cost (that is, increased allocative efficiency). The aim of the paper is to analyze the trend of both the efficiency components during the regulated period from 1992-93 to 2004-05 and investigate whether the regulatory price reviews succeeded in the purpose of encouraging convergence towards higher efficiency.

Following the first price control set by the Government at privatization in 1989, new price reviews have been set in 1994, 1999 and 2004 at intervals of five years. ${ }^{2}$ Given the data available, we will be able to analyze the impact of the 1994 and 1999 price reviews.

\footnotetext{
${ }^{1}$ The first price control, for the period 1989 to 1994, was set by the Government. OFWAT has set the subsequent ones.

${ }^{2}$ In reality, the price cap in 1989 was set for a ten-year period, with an opportunity for the regulator to hold an interim determination after five years, which the regulator implemented. A debate rose regarding the desirability of maintaining a five-year cyclical review as the firms may have greater incentive to outperform the regulatory targets in the initial years of the five-year price control period in order to keep the benefits for a longer time before passing them to the customers through the successive price regulation. A longer price setting period might induce the firms to outperform the regulatory assumptions for a higher number of years. In 1999, OFWAT proposed a rolling incentive mechanism which it believed would have strengthened the firms' incentive to cost reduction, allowing them keeping the benefits for a full-five years period, irrespective of when the target outperform was made.
} 
Following privatization, prices for the water and sewerage service rose, on average, by almost 30\% during the years up to the 1994 price review (Saal and Parker, 2000), thus providing firms with the financial resources necessary to sustain their capital investments. The 1994 price review set an average real annual increase of $1.5 \%$ up to 1999, with the expectation of a further real increase by $0.6 \%$ per year over the following five years (OFWAT, 1994). However, with the 1999 price review, the regulator reduced prices by $12.3 \%$, on average, for the first year of the new period. The average annual real reduction over the five years as a whole was $2 \% .^{3}$

The 2004 price review, however, did not continue in this way, as it allowed an average annual increase over the whole five-year period 2004-2008 of 4.3\%.

The 1999 review thus, signaled a change in regulatory policy and concentrated the greatest part of the price reduction in one year. This raises the question of whether this would motivate firms to achieve higher levels of efficiency growth. ${ }^{4}$ A standard answer to this question may be that a price cap, which makes prices exogenous for a specified period, should provide broadly similar incentives for cost reduction however challenging the targets. However, it is also known that a fixed term price control furnishes weaker incentives for efficiency towards the end of the control period, as a result of the so-called "ratchet effect" - the tendency for regulators to use cost performance at the end of the control period as a basis for setting prices for the next period. If the regulator not only extrapolates from the level of costs when setting the next price cap but also notes their rate of decline, a firm may be reluctant to put in a very sparkling performance in any price control period in case it receives tougher cost reduction targets in the next period. More demanding targets may elicit different behavior in this regard, by removing the option on pain of the firm failing to make a profit of eking out cost reductions over time.

At the same time, privatization should have removed the implicit distortion found in public firms, such as the overuse of employment for social and political reasons, so allowing the regulation policy being more effective. We examine what the data tell us about the importance of these various effects.

\section{Previous empirical literature}

In this section, we present a brief description of previous empirical studies that have been conducted on the economic analysis of the water and the integrated water and sewerage industry, in both the UK and other countries.

The first point of interest concerns the analysis of cost efficiency. As far as the UK experience is concerned, a few early papers attempted to evaluate the firms' cost efficiency and total factor productivity after the privatization of the industry, as well as to establish the impact of regulation.

Stewart (1993, 1994) investigated water and sewerage costs separately, using an econometric frontier approach. The results are shown to depend on the distributional assumption employed in the econometric specification.

\footnotetext{
${ }^{3}$ After the first price reduction, the regulator set a further decrease by $-0.4 \%$ for the financial year 2001-02 and increases by $+0.2 \%,+1.3 \%$ and $+1.7 \%$ for the last three years. These figures are averages across the industry.

${ }^{4}$ For a discussion of the impact of price controls, see Armstrong and Sappington (2007).
} 
Ashton (2000a) analyzed the firm-specific cost efficiency conditions of the UK water and sewerage privatized companies as combined entities over the period between 1987 and 1997, using a translog variable cost specification. This study finds a moderate level of dispersion of average inefficiency, which could be indicative of the diversity both of operating environment and of performance in the sector. In another contribution, Ashton (2000b) identified the dynamic aspects of performance of the privatized WaSCs between 1989 and 1997, exploring the characteristics of the total factor productivity growth. The results highlight a decline in total factor productivity and technical change, thus drawing the attention to the modest impact of privatization since 1989.

A joint consideration of the effect of privatization and regulation on economic efficiency was carried out by Saal and Parker (2000). This study modeled the ten WaSCs, using observations between 1985 and 1999, using a multi-output translog total cost function. The findings suggest that technological change has been labor-saving and capitalaugmenting. The hypotheses of different total cost growth rate after privatization and the 1994 price review were tested. While the former hypothesis was rejected, revealing that no effect could be found due to privatization, the second one was not, suggesting that the main source of cost efficiency might be found in industry regulation. In another contribution, Saal and Parker (2001) employed labor and total factor productivity (TFP) indices and rejected the hypothesis of increasing overall productivity due to privatization, even though labor productivity showed a significant growth rate. As they argued, this may be ascribed to a decreasing trend in capital productivity, due to capital for labor substitution in the post-privatization period and the failure of the regulator to counteract the tendency towards over-investment. ${ }^{5}$ They also found that, although gains in labor productivity mainly took place after the 1994 price review, the overall productivity growth declined after 1994 . Further results are found in Saal and Parker (2004), where no evidence is found that privatization led to a TFP growth but there is some evidence of improving TFP owing to the 1994 price control. In a more extensive study, Saal and Reid (2004), employing a quality adjusted translog variable cost function, showed that while the 1994 price review improved operating cost productivity, the 1999 price review did not provide evidence of a further productivity growth rate. Saal et al (forthcoming) adopt an input distance function approach in order to decompose productivity growth into technical change, efficiency change and scale efficiency change. This study claims that while technical change occurred as a consequence of privatization, efficiency improvements did not come about because the regulatory price control was lax. Bottasso and Conti (2003) also found evidence that operating cost inefficiency was decreasing and that the inefficiency differentials were narrowing for the whole English and Welsh water industry between 1995 and 2001.

Looking elsewhere the role of regulatory policy has been recently examined by Aubert and Reynaud (2005) for the Wisconsin water system. The particular Wisconsin regulation scheme, based on the simultaneous presence of price-cap and rate-of-return schemes in the same region at the same time, allowed the authors to compare the effect of the two different regulatory regimes. Using a stochastic cost frontier approach (where the inefficiency error term is modeled as a function of the regulatory type), they surprisingly conclude that the most efficient utilities are those operating under a rate-of-return regime ${ }^{6}$

\footnotetext{
${ }^{5}$ This process is mainly explained by the authors in terms of the environmental constraints that forced the privatised companies into extensive investment programmes.

${ }^{6}$ Rate-of-return regulation emerged for limiting the profits of franchised monopolies. It consists in letting the firms to freely choose their price under the constraint that return on capital should be fair but below a pre-
} 
and subject to extensive information gathering by the regulator. Price-cap regulation was shown to be a higher-powered incentive mechanism than a hybrid regulatory scheme with less information available for the regulator. The need for the regulator to gather information in order to enforce an effective yardstick competition system is also emphasized by Anwandter and Ozuna (2002), in the context of the public water industry reform in Mexico.

Evidence of poor results of private ownership, given the monopolistic nature of the service, can be found in other studies. Feigenbaum and Teeples (1983), using a sample of government and privately-owned U.S. water suppliers suggest that, contrary to public choice or property rights theories, no evidence could be found of significant differences in the cost functions of public versus private utilities. Bhattacharyya et al (1994) and Bhattacharyya et al (1995a and 1995b) modeled the cost structure of a sample of U.S. water utilities embodying the potential input allocative distortion attributable to the ownership nature. ${ }^{7}$ The main results highlight a better efficiency performance of the public firms at least when they are large. Lambert et al (1993) examined the question of the ownership structure for U.S. water system using a linear programming approach. They found no difference between private and public categories in selecting the least cost combination of inputs.

An alternative method for modeling the technology and assessing efficiency performance is via DEA (Data Envelopment Analysis), although DEA was criticized by OFWAT in 1994 as a means of setting price limits. A comprehensive description of the use of DEA for regulatory purposes is provided in Thanassoulis (2000a and 2000b), where DEA methodology has been employed with the aim of estimating the potential operating cost savings for the water function. These studies also address the issue of how to represent the technology. Other applications of DEA can be found in Tupper and Resende (2004) in the context of the Brazilian water and sewerage system and in Coelli and Walding (2006) in the context of the Australian water industry. The former, in particular, provides a second stage correction of the DEA efficiency scores in order to account for regional operational heterogeneities (density effects and water losses). Cubbin and Tzanidakis (1998) carried out a comparison between regression analysis and DEA for the UK water industry using 1994-95 data. This study concludes that DEA analysis could be useful in identifying possible reasons for poor performance but it is to be used with caution where large datasets are not available.

Summarizing, as far as the UK context is concerned, analysis of the impact of regulation has been generally limited to the 1994 price review - with the exception of the study by Saal and Reid (2004) - and the findings show a scant evidence of efficiency growth. The 1999 price review tightened the regulation scheme, imposing for the first time a price reduction. The dataset used in this study covers the period from 1992-93 to 2004-05 for the ten WaSCs, and although it does not allow us directly to consider the impact of

specified level. This method allows prices to increase for covering costs and, in such a way, it is expected to provide less incentives to pursue cost efficiency.

${ }^{7}$ In these studies, the authors employed a generalised or shadow cost function approach (Kumbhakar, 1992; Parker, 1995, Maietta, 2000; Kumbhakar and Sarkar, 2003) which accommodates the possible violation that arises when costs are minimised with respect to internal (shadow) prices rather than market input prices. The input price distortions bring about allocative inefficiency. The application of this methodology may be particularly suitable for public utilities, as they are often subject to the public control. It is also to be noted that an alternative solution to the problem of not exogenous input prices consists in the use of an inputdistance function (see Saal and Parker, 2004), since this method does not require information on prices. 
privatization on efficiency, it allows us to test the effects of two subsequent price reviews. This makes it possible to address the question of whether tightening the regulatory regime succeeded in improving the cost efficiency of the industry. Furthermore, from a methodological viewpoint, this study seeks to shed some light on allocative efficiency, which has received so far limited attention in the empirical literature.

\section{Model specification}

In 1957, Farrell introduced a methodology for the measurement of the economic efficiency, as well as its decomposition into both technical and allocative components. From an input-oriented perspective ${ }^{8}$, technical efficiency $(T E)$ is associated with the ability to produce on the efficiency boundary of the production possibility set given a predetermined quantity of output (point $E$ in figure 1), whereas allocative efficiency $(A E)$ reflects the ability to produce at a given output level using the optimal input mix (point $E$, in figure 1).

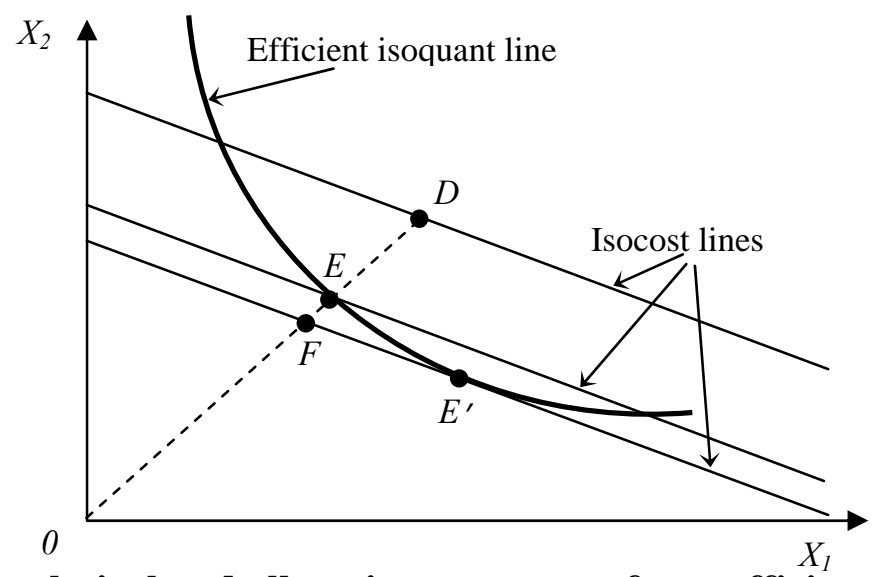

Figure 1: Global, technical and allocative measures of cost efficiency

Note: Two inputs $\left(\mathrm{x}_{1}\right.$ and $\mathrm{x}_{2}$ ) and one output technology. Technical efficiency $=$ OE/OD; Allocative efficiency $=$ OF/OE; Economic efficiency $=\mathrm{OF} / \mathrm{OD}=(\mathrm{OF} / \mathrm{OE}) \times(\mathrm{OE} / \mathrm{OD})$

Let $N$ [with $n=1, \ldots, N$ ] be the number of Decision Making Units (DMUs), $x_{i}$ the $i$-th input $[i=1 \ldots I]$ and $y_{j}$ the $j$-th output $[j=1 \ldots J$. Then, the input-oriented radial measure of technical efficiency $\left(T E_{I}\right)$ is calculated by solving, for each DMU, the following linear programming problem (Charnes, Cooper and Rhodes, 1978; Banker, Charnes and Cooper 1984), under the assumption of variable returns to scale $(V R S)^{9}$ :

\footnotetext{
${ }^{8}$ In principle, the economic efficiency may be measured using an input or an output-oriented approach. In the first case, the input use is minimized given a certain amount of output, while in the second the output is maximized for a given level of inputs. Generally, the adoption of an input-oriented framework is preferred when public utilities are considered as the demand of service the suppliers must provide may be seen as exogenous (see Torres and Morrison Paul, 2006, for an application with endogenous output).

${ }^{9}$ For a comprehensive description of DEA models, see Thanassoulis (2001) and Coelli et al (2005). The VRS (Variable Returns to Scale) model here adopted ensures - through the convexity constraint that a DMU
} 


$$
\begin{aligned}
& \min T E_{I}-\varepsilon\left(\sum_{i=1}^{I} S_{i}+\sum_{j=1}^{J} S_{j}\right) \\
& T E_{I} x_{i}-S_{i}=\sum_{n=1}^{N} \lambda_{n} x_{i n} \quad i=1 \ldots I \\
& y_{j}+S_{j}=\sum_{n=1}^{N} \lambda_{n} y_{j n} \quad j=1 \ldots J \\
& \sum_{n=1}^{N} \lambda_{n}=1 \\
& \lambda_{n}, S_{i}, S_{j} \geq 0
\end{aligned}
$$

where $S_{i}$ and $S_{j}$ indicate the slacks (that is, non-radial input reduction measures) for $i$-th input and $j$-th output respectively, $\varepsilon$ is an infinitesimal and $\lambda_{n}$ is an intensity variable assigned to each DMU, which assumes non-zero value for the efficient DMUs (that is, those lying on the efficiency frontier) which are the peers for the inefficient ones. The scalar $T E_{I}$ ranges from 0 to 1 , being equal to unity when full technical efficiency occurs.

The allocative efficiency measure allows us to assess the potential to reduce costs further by means of a variation in the input mix, consistently with the existing technology. The DMU's cost-minimising input demand $\left(x_{i}{ }^{*}\right)$ may be calculated by solving, for each DMU, the following VRS linear programming problem (Coelli et al, 2005):

$$
\begin{aligned}
& \min \sum_{i=1}^{I} w_{i} x_{i}^{*} \\
& x_{i}^{*} \geq \sum_{n=1}^{N} \lambda_{n} x_{i n} \quad i=1 \ldots I \\
& y_{j} \leq \sum_{n=1}^{N} \lambda_{n} y_{j n} \quad j=1 \ldots J \\
& \sum_{n=1}^{N} \lambda_{n}=1 \\
& \lambda_{n}, x_{i}^{*} \geq 0
\end{aligned}
$$

Hence, the allocative efficiency measure is calculated as the ratio of minimum attainable cost to the cost corresponding to a situation wherein all inputs are contracted by the same proportion $\left(1-T E_{I}\right)$ in order to eliminate technical inefficiency, as follows:

$$
A E=\frac{\sum_{i=1}^{I} w_{i} x_{i}^{*}}{\sum_{i=1}^{I} w_{i}\left(T E_{I}\right) x_{i}}
$$

is compared with units operating at a similar size. In this way, this model allows separating the pure managerial inefficiency from the inefficiency entirely due to an incorrect size setting. 
The basic DEA model described here evaluates economic efficiency using traditional input and output variables but it does not consider the potential role that environmental factors may have on producers’ performance. ${ }^{10}$

Several models have been developed in order to incorporate environmental effects into a DEA-based performance evaluation. ${ }^{11}$ One possible approach is to include the environmental variables directly into the linear programming formulation either as nondiscretionary inputs, outputs or neutral variables, according to the circumstances (Ferrier and Lovell, 1990). This requires that further linear programming constraints be included. As a consequence, only few environmental variables can simultaneously be taken into account to avoid excessive restriction of the reference set, hence reduction of the discriminatory power of DEA.

Another possible approach is to adopt a multi-stage DEA analysis aimed at ensuring that the comparison is made among units which operate under similar environmental conditions, so eliminating the environmental effects from the single producer's performance assessment. In this way, the evaluation of the impact of the environmental effects may be carried out either when an a priori direction of the influence of the environmental variable upon efficiency is known (Banker and Morey, 1986) or not (Charnes et al, 1981).

Both these approaches are, however, deterministic and so they fail to take into consideration the effects of statistical noise on efficiency performance. Another group of models is based on two-stage mixed approaches, which involve solving a DEA problem in a first stage using traditional input and output variables, in order to calculate initial efficiency measures. The efficiency scores are then regressed upon a set of environmental variables in a second stage, the objective being to determine the signs, as well as the significance of the coefficients of the environmental variables and to consider the impact of noise. McCarty and Yaisawarng (1993) and Bhattacharyya et al (1997) tried to account for noise using the residuals of the regression to adjust the first-stage DEA efficiency scores. Fried et al (1999) introduced a three-stage approach where the initial DEA efficiency scores are regressed upon a vector of environmental factors. Predicted values of the impact of the environmental effects can be then computed. In a third stage, the original data are adjusted to account for the effect of environmental variables and DEA is re-run in order to obtain new DEA scores unaffected by environmental characteristics. This approach, however, is unable to account for the role of statistical noise on efficiency. ${ }^{12}$

In order to embody the action of both environmental variables and statistical noise upon efficiency, we adopted a novel three-stage approach proposed by Fried et al (2002). By adopting, a mixed approach which combines DEA and Stochastic Frontier Approach (SFA), their model makes it possible to obtain a measure of the intrinsic managerial ability

\footnotetext{
${ }^{10}$ Some examples of environmental factors that may affect firms' performance include characteristics, such as ownership nature, geographical location, regulatory regime and so on (Fried et al, 1999).

${ }^{11}$ See Coelli et al (2005) for wide details on these models.

${ }^{12}$ In general, it is important to recognize that - as noted in the DEA literature - all the multi-stage mixed approaches may present problems if the variables used in the first stage (inputs and outputs) were highly correlated with the set of variables used in the second stage; the resulting second-stage coefficients would then be biased. Moreover, whether in the first DEA stage some relevant inputs or outputs were omitted, the technology would be incorrectly specified and the efficiency scores inappropriate for use in the second-stage regression.
} 
shown in organizing firms' operations, separately both from the impacts of the environmental characteristics in which production takes place and from random noise.

Note that, although the Fried et al (2002) approach was originally proposed to model DEA-based technical inefficiency measures, it has been extended in this study to incorporate also allocative inefficiency. The model is briefly summarized here.

According to Fried et al (2002), the difference between the observed input-specific usage, $x_{i}(i=1, \ldots, I)$, and the optimal projected value onto the efficient boundary, $T E_{I} \times x_{i}$ (where the technical efficiency score, $T E_{I}$, is derived from the DEA linear programming (1)), is viewed as the excess use (or over-use) of the $i$-th input. Such excess use may be explained by pure managerial technical inefficiency, environmental effects and random noise. In this light, these input-specific overuse measures derived for all the observations from the first stage have been regressed over a set of environmental variables using SFA, as described below ${ }^{13}$ :

$$
\left(x_{i}-T E_{I} x_{i}\right)=f(z ; \beta)+u+v \quad \forall i=1, \ldots, I
$$

where $z=\left[z_{1 n}, \ldots, z_{K n}\right]$ is a vector of $K$ environmental variables outside the control of managers, $\beta$ is a vector of parameters to be estimated, $u$ is a non-negative half-normal distributed $N^{+}\left(0, \sigma_{u}^{2}\right)$ error term ${ }^{14}$, which captures the over-use of the $i$-th input brought about by pure managerial inefficiency, and $v$ is the usual normally distributed $N\left(0, \sigma_{v}{ }^{2}\right)$ error term. ${ }^{15}$

As in equation (4), the $i$-th input allocative distortion, obtained as difference between the technically optimum input level and the cost-minimizing input demand $\left(x_{i}^{*}\right)$, has been regressed using SFA on a set of variables which enable to control for the impact of environmental factors. In this case, as the input distortion could be either positive or negative, we considered, on the left-hand side of equation (5), the absolute value of the difference $^{16}$, as follows:

$$
\left|T E_{I} x_{i}-x_{i}^{*}\right|=f(z ; \beta)+u+v \quad \forall i=1, \ldots, I
$$

\footnotetext{
${ }^{13}$ It should be noted that in the Fried et al (2002) method total (radial plus non-radial) measures of input slacks (interpreted as input over-use measures) are regressed against a set of observable environmental variables using SFA, where total input slacks are calculated, following the linear programming problem (1), as $x_{i}-\left(T E_{I} \times x_{i}-S_{i}\right)=x_{i} \times\left(1-T E_{I}\right)+S_{i}(\forall i=1, \ldots, I)$. Differently, our second stage estimates are solely based on radial - rather than total - input slacks, expressed as $x_{i}-T E_{I} \times x_{i}(\forall i=1, \ldots, I)$. The attempt to disentangle technical from allocative inefficiency led us to include non-radial input slacks, $S_{i}$, into the allocative distortion equations, as the potential non-radial contraction of specific inputs reflects the adjustment of an inappropriate input mix (Coelli et al, 2005; Ferrier and Lovell, 1990).

${ }^{14}$ In this paper, a half-normal distribution has been adopted rather than a more general truncated-normal specification of the inefficiency term, in order to minimise computational problems. Although the truncatednormal specification is more general, we do not think that this assumption creates serious problems.

${ }^{15}$ For completeness, in Fried et al (2002), a third stage is defined in which DEA is re-run once original data are adjusted in order to remove the impact of environmental variables and noise. Since the calculation of firms' ranking is beyond the aim of this paper, we decided to skip this stage.

${ }^{16}$ The left-hand side difference in equation (5) should be considered as a mere distortion measure as it only allows considering if distortion is systematically explained by external or internal factors, without distinguishing between input-specific over or under-utilisation.
} 
where $z, \beta$ and $v$ have the same meaning as above. In this case, the inefficiency term $u \geq 0$ should be interpreted as the intrinsic inability of the managers to arrange the input mix, given the relative input prices, in order to attain minimum cost.

One advantage of this methodology with respect to the stochastic cost frontier approach is that it allows separating the technical and the allocative efficiency components in an easy way. For each component then, it involves the estimation of $I$ separate secondstage equations, thus letting features of operating environment, pure managerial inefficiency and statistical noise exert different impact across inputs. In addition, it allows separating the technical from the allocative efficiency.

In order to capture the (technical and allocative) inefficiency trend over time, the inefficiency error terms, $u$, have been modeled, either in equations (4) or (5), according to the time-varying inefficiency model defined in Battese and Coelli (1992):

$$
u_{n t}=\left(e^{-\eta(t-T)}\right) \times u_{n T}
$$

where $n=1, \ldots, N$ denotes the firm, $t=1 \ldots T$ denotes the time, $T$ indicates the final year of the time series for each firm, $\eta$ is a parameter to be estimated and $u_{T}$ is assumed to have an i.i.d. half-normal distribution $N^{+}\left(0, \sigma_{u}^{2}\right)$. A positive value of $\eta$ implies a downward trend in the managerial efficiency term over time while a negative value implies an upward trend. Thus, the trend of the managerial inefficiency for each input, along with its statistical significance, is directly derived from the data once both environmental factors and noise have been removed.

As regards this point, it should be acknowledged that a restrictive assumption applies in the sense that all the firms are assumed to be characterized by a similar trend of the inefficiency term over time. This could be seen as a regrettable restriction of the model. Nonetheless, it may be argued that all the England and Wales WaSCs share very similar regulatory conditions and, as a consequence, the restrictions enforced by the central regulator are likely to guide firms in a common direction.

\section{Specification of the technology using DEA}

A fundamental stage in DEA is the correct identification of the multiple-input multipleoutput bundles, so that firms can be compared taking into consideration all the activities they carry out (Thanassoulis, 2001).

With respect to the industry under investigation, the first activity concerns the extraction and treatment of water from rivers or boreholes. Once water has been abstracted and treated to meet quality parameters, it is pumped into the mains and delivered to household or non-household customers through the distribution network. A second set of activities deals with the collection of waste water through the sewage network and the disposal of the effluent in the sewage treatment works so that water can be returned to its natural environment. There is a body of literature that attempts to model water and sewerage technology and cost structure (among the others, see the studies of Fabbri and Fraquelli, 2000; Garcia and Thomas, 2001; Mizutani and Urakami, 2001; Torres and Morrison Paul, 2006). The choice of inputs and outputs described below is generally consistent with this literature. 
Using this scheme, we identified four outputs, each of them able to capture a specific resource-consuming phase of the overall transformation process.

First, the total volume of delivered potable plus non potable water (WDEL) has been used as the output of the abstraction and treatment phase. This is a conventional measure of the water production activity. An alternative measure, also tested in this work without significant changes in the results, is the distribution input, which is defined as the amount of water entering the distribution system, including the water losses along the distribution network.

Second, the total number of household and non-household water service-connected properties (WPROP) has been adopted as proxy for the scale of the distribution activity.

Third, the total number of household and non-household sewerage service-connected properties $(S P R O P)$ has been used as to capture the scope of the waste water collection activity.

Finally, the physical amount of waste water (WASTW) has been included as output of the effluent disposal and treatment activity.

One important characteristic of water companies is that they must comply with drinking water quality standards (issued by DWI) and river quality standards (issued by EA). Thus, water quality could be regarded as an additional output since the fulfillment of quality programs is usually highly expensive. However, instead of considering water quality as a separate output we adopted the solution, suggested by Saal and Parker (2000), of adjusting the $W D E L$ variable by a firm-specific compliance index with drinking water quality standards and $W A S T W$ by a firm-specific water quality compliance index with river quality standards. Both compliance indices have been standardized with respect to the average England and Wales compliance levels. ${ }^{17}$

In order to model the production process, we used three inputs: labour, other operating expenditures and capital. All the variables have been expressed in 2002-03 prices.

Labour input (EMPL) is measured by the total cost of non-manual and manual manpower which is directly attributable to the water and sewerage businesses. In order to obtain a proxy for the physical use of labour, we adjusted this variable by a firm-specific labour price index. ${ }^{18}$

The other operating expenditures variable (OTHEX) has been calculated by subtracting the cost of labour from the total operating expenditures $(O P E X)$ for the appointed water and sewerage businesses, and it includes the cost of materials and consumables, hired services and energy (see Ashton 2000a and 2000b for a similar approach). Since the price of energy followed a decreasing trend both in real and nominal terms - the fall in the price of energy for the industrial sector is about $20 \%$ in current terms and $60 \%$ in nominal terms from 1993 to 2005 - it was impossible to deflate this aggregate value using a common price index. Therefore, we deflated the materials and services cost and the energy cost through two different indices. The former has been adjusted by the conventional RPI

\footnotetext{
${ }^{17}$ Consistent time series of drinking water and river quality compliance indices have been taken from the DWI and the EA annual reports.

${ }^{18}$ The labour price index is based on the trend of the average wage for each firm. In turn, the average wage has been calculated dividing the total employment cost by the number of full total equivalent employees (the information has been taken from the annual reports of the companies). This is the best available proxy of the yearly average wage for the water and sewerage industry. The resulting wages have been then compared with the data from the New Earnings Survey and this confirmed their validity. We preferred to use this specification of the labour input instead of directly using the number of employees since the latter sometimes relates to the whole group, so including workers of non appointed businesses.
} 
index; the latter by an energy price index for the industrial sector derived from the Department for Trade and Industry (DTI). ${ }^{19}$

Capital expenditure (CAPEX) has been included in the DEA specification because of the capital-intensive nature of the water and sewerage industry (Saal and Parker, 2000, 2001; Saal et al, forthcoming; Coelli and Walding, 2006). The annual capital consumption has been calculated by multiplying the yearly monetary value of capital, given by the annual average modern equivalent asset (MEA) estimation of the replacement cost of fixed tangible assets ${ }^{20}$, by a depreciation rate. This latter was derived on the basis of the current depreciation and infrastructure renewal charges ${ }^{21}$, directly attributed to water and sewerage businesses, divided by the average MEA gross capital value in the same year. In this way, the consumption of capital, as captured by $C A P E X$, is proportional to the stock of capital.

Some descriptive statistics on output and input variables are presented in Table 1.

\begin{tabular}{|ll|l|l|l|l|l|}
\hline Variable & & Mean & $\begin{array}{l}\text { Standard } \\
\text { deviation }\end{array}$ & $\begin{array}{l}\text { Variation } \\
\text { coefficient }\end{array}$ & Min & Max \\
\hline WDEL & $(\mathrm{Ml} / \mathrm{d})$ & 1072.5 & 560.1 & 0.522 & 288.9 & 2179.4 \\
\hline WPROP & $(000)$ & 1895.3 & 1016.6 & 0.536 & 455.8 & 3684.1 \\
\hline SPROP & $(000)$ & 2123.5 & 1292.9 & 0.608 & 565.9 & 5272.3 \\
\hline WASTW & $(\mathrm{Ml} / \mathrm{d})$ & 1036.0 & 703.2 & 0.678 & 246.6 & 3020.0 \\
\hline EMPL & $(£ \mathrm{~m})$ & 34.1 & 20.7 & 0.607 & 7.7 & 137.5 \\
\hline OTHEX & $(£ \mathrm{~m})$ & 226.1 & 108.6 & 0.480 & 69.2 & 446.1 \\
\hline CAPEX & $(£ \mathrm{~m})$ & 181.4 & 85.7 & 0.472 & 38.2 & 361.7 \\
\hline
\end{tabular}

\section{Table 1: Descriptive statistics}

In order to derive the contribution of allocative efficiency to overall economic efficiency, input price data are needed. A deflation procedure based on 2002-03 has been followed, in order to isolate the real movements of prices.

A price of labor has been calculated by dividing the overall cost of employment by the number of full time equivalent employees (see note 18) and then deflating the resulting values by the RPI index.

A price for other operating expenditures is problematic, given the heterogeneous nature of this input. We adopted a weighted average of RPI and a real price index of energy for

\footnotetext{
${ }^{19}$ Different energy price indices are available. We considered the energy price index for industrial use expressed in current terms and including the climate levy charge for UK.

${ }^{20}$ Following Stone and Webster (2004), the MEA values available in the OFWAT dataset have been deflated using the Construction Price Index (COPI) as deflation index instead of the RPI index. Furthermore, the MEA annual values have been corrected in order to eliminate the impact due to AMP adjustments - that is, periodic capital value adjustments to bring assets to their current values according to their operational standards. This smoothing of the capital stock time series has been carried out considering the MEA value in the financial year 2002-03 as base and then adding (for the successive years) or subtracting (for the previous years) the amount of the annual net investments, calculated for each year at 2002-03 prices.

${ }^{21}$ The depreciation regime is different according to the type of asset. While above ground assets (like treatment plants, pumps, reservoirs, sewage disposal works) are depreciated, the underground assets are not directly depreciated but an infrastructure renewals charge is computed and included in the Profit and Loss statement.
} 
the industrial sector, taken from DTI, where the weights are represented by the respective cost shares. $^{22}$

Finally, the price of capital has been computed as the percentage rate resulting from the sum of the above described depreciation (and infrastructure renewal) rate and the opportunity cost of capital. ${ }^{23}$ The latter has been directly imputed from the regulatory assessment of the fair rate of return on the capital employed. According to OFWAT, the cost of capital cost was equal 5.5\% up to 1999 and $4.75 \%$ for the subsequent years.

In addition, it should be noted that the inclusion of four output variables ensures that the comparison is made among firms with similar customer density (where customer density is measured as volumes per customer) and similar relations between water and sewerage activities. Furthermore, comparison between firms which are similar in terms of network density (where network density is measured as customers per kilometre of network) is also indirectly accommodated. Low network density firms are generally more capital-intensive than high network density firms. Therefore, the joint consideration of operating and capital expenditures ensures that the comparison is made among firms with similar input ratios, that is, with comparable network density conditions (Coelli and Walding, 2006).

\section{$6 \quad$ Environmental and regulatory variables}

The efficiency of a firm could be affected by exogenous conditions that are not under the direct control of managers. These effects should be removed in an efficiency assessment. The exogenous variables we used in the second stage are of two types: environmental variables and policy variables. The former take account of the impact of the different characteristics of the network and of the area where the service is provided, thus control for heterogeneity among firms. The latter relate to regulatory policy and more specifically, the change in the economic environment that occurs after the introduction of new regulatory constraints. These variables are not differentiated by firms since the regulatory framework is common for the whole industry but they vary over time.

The set of environmental variables should be such as to represent the exogenous characteristics of the whole range of activities. Our set of environmental variables is consistent with many of the above mentioned empirical studies. We now briefly describe these variables.

\footnotetext{
${ }^{22}$ A better solution may have been to disentangle material and services from energy. In this latter case, the first choice for the energy price would have been a measure calculated by dividing the cost of power by the consumption of energy but unfortunately, no consumption value is available in the OFWAT dataset. The most natural alternative would have been to use an energy price index but in this case, we must have employed two price indices (the RPI index and the DTI energy price index) invariant across firms. On the contrary, the weighted average price index here adopted is variant, given that the cost shares vary across firms and years.

The DTI real energy price index has been deflated using the GDP deflator. We recomputed the energy price time series index using the RPI index but no significant difference emerged.

${ }^{23}$ The notion of user cost of capital is based on the view that capital should be considered under both a physical and financial perspective. Indeed "...the capital cost the firm truly incurs is an implicit rental price ..., which is the interest rate on the investment price, plus the deterioration involved, ...” (Morrison Paul, 1999, p.286). For a similar approach see also Mizutani and Urakami (2001).
} 
The proportion of water abstracted from underground sources (SOURCE) reflects the different conditions of water production. A larger amount of abstraction from boreholes than from surface sources requires higher power consumption but at the same time, less treatment cost because of the higher purity of underground water. With regard to capital, a higher proportion of underground water requires more pumps while a higher proportion of surface water is associated to a larger number of treatment plants. For these reasons, we assign no a priori impact to this variable.

The percentage of water losses (WLOSS) with respect to the overall distribution input is a general proxy for the operational condition of the distribution network. A higher proportion of losses implies more critical conditions of the network, thus a higher input use is expected.

The water population density (WDENS) is calculated as the ratio between the population provided with water and the length of water distribution network. In a rough way, a higher density could also be associated to a greater proportion of household properties. In general, providing service to a more concentrated population is cheaper - per connection - than serving a dispersed population, since in this latter case more diversions of the network, more frequent maintenance and more energy are needed.

The sewerage population density (SDENS) is calculated as the ratio between the equivalent sewerage population and the length of the sewerage network. A higher density could be associated to a high proportion of household properties connected. Analogous economies of density arguments, as described above for the water activity, apply even though a more ambiguous effect has been empirically found (see Tupper and Resende, 2004). ${ }^{24}$

Since sewerage population density could not entirely capture the effect due to the users' composition, we also considered the trade effluent variable (TREFFL), which represents the proportion of industrial effluent in total waste water. In general, we would expect that more industrial effluent would impose higher input requirements, especially with respect to treatment cost and energy.

Time trend (TIME) is included to account for technological progress/regress. The TIME variable is interpreted as a proxy for technological changes but not for changes in technical efficiency conditions, which are embodied in the one-sided distributed error component. Furthermore, as privately-owned firms are profit-maximizing agents, we would expect that technical progress was encouraged after privatization.

Finally, regulatory variables have been introduced to take into account the potential impact of changes in the economic environment. Because there have been two price controls during the period under observation, we introduced in the model two distinct dummy variables, $R E G 94$ and $R E G 99$, which assume a value of one for the five years after respectively, 1994 and $1999 .{ }^{25}$ As noted above, the second regulatory intervention was more severe. Hence, we may expect a stronger input-reducing impact associated with the REG99 variable.

The managerial (technical and allocative) inefficiency is embodied into the one-sided inefficiency error terms $(u)$ in equations (4) and (5). The unidirectional efficiency trend is

\footnotetext{
${ }^{24}$ The WDENS and SDENS variables are expected to capture more effects than those ones already accommodated by the multi-input DEA specification. WDENS and SDENS use the population rather than the number of customers and they are included to reflect the different operational characteristics associated to the network conformation.

${ }^{25}$ It should be noted that the allowed price changes took effect on 1 April 1995 and 1 April 2000.
} 
directly estimated by the model. This inefficiency error component should be interpreted as the residual inefficiency of the firms if they faced the same environmental and noise conditions, and they operated in a neutral context with respect to regulatory policy and technical progress/regress. Thus, another reason has to be sought to explain the inefficiency terms level and trend. Since the water and sewerage companies were subjected to a privatization process in 1989, the change in ownership regime could be interpreted as driver of the managerial inefficiency trend. As stated above, private firms are usually viewed as focusing more on profit-maximizing (or cost-minimizing) behavior than public firms, so that they can be expected to make more effort for the rationalization of the input consumption. Moreover, the introduction of a yardstick competition regime in the period after privatization could have well worked as an incentive mechanism as it allowed a firm's performance to be judged in relation to the performance of the other units. ${ }^{26}$ At least in the long run, this could be expected to narrow the efficiency differentials and to induce the firms to reduce costs. For these reasons, we should expect a positive efficiency trend that is, a convergence towards an optimal use of inputs from both a technical and an allocative viewpoint. ${ }^{27}$

\section{$7 \quad$ Empirical results}

\subsection{DEA technical and allocative efficiency results}

The first stage DEA results are shown in Table 2. The mean technical efficiency score is equal to 0.909, which indicates that the average firm could reduce all inputs simultaneously by $9.1 \%$, still producing the same amount of output.

The minimum value is 0.657 , indicating that there were substantial differences among firms. The mean allocative efficiency score is 0.810 , a very low level, which indicates that, even if technical efficiency were achieved, a 19.0\% excess of total operating (capital plus non capital) cost over minimum cost there would still exist, which could be eliminated by adjusting the inappropriate input mix. The minimum score is 0.349 , revealing the presence of very large allocative distortions. ${ }^{28}$ Moreover, the variability of the allocative scores is higher that that of technical efficiency. These results indicate that a major part of the

\footnotetext{
${ }^{26}$ OFWAT has placed considerable emphasis on yardstick competition in price cap setting. By using the results of econometric studies of the regulated firms which relate costs to internal input organisation and environmental variables, OFWAT is able to set out "catch-up" efficiency targets that contribute to the determination of the price cap for individual companies. The determination process also makes adjustments for events that are beyond the companies' control and rewards or penalises service quality performance. The final decision on price caps thus reflects OFWAT's assessment of each company's performance relative to the industry as a whole.

${ }^{27}$ While the regulation and time variables have been used as explanatory factors for both the technical and allocative frameworks, the set of operational characteristics have been consider to have only a technical nature. This is consistent with several papers within the shadow cost function approach literature stream which only use regulation, ownership and time as potential explanatory factors for allocative distortions. ${ }^{28}$ Actually, this value appears very low but when we move to the first decile the allocative efficiency level increases to 0.622 , thus revealing a more credible assessment of the allocative inefficiency in such extreme situations. Anyway, very low level of allocative (as well as technical) efficiency could also be found in many empirical researches using DEA (see, for instance, Coelli et al (2002)).
} 
economic efficiency is attributable to allocative distortions in input utilization, rather than to technical inefficiency.

\begin{tabular}{|l|l|l|}
\hline & TE (1993-2005) & AE(1993-2005) \\
\hline Mean & 0.909 & 0.810 \\
\hline Min & 0.657 & 0.349 \\
\hline Standard deviation & 0.103 & 0.147 \\
\hline
\end{tabular}

Table 2: Average technical and allocative efficiency

A) Technical efficiency trend

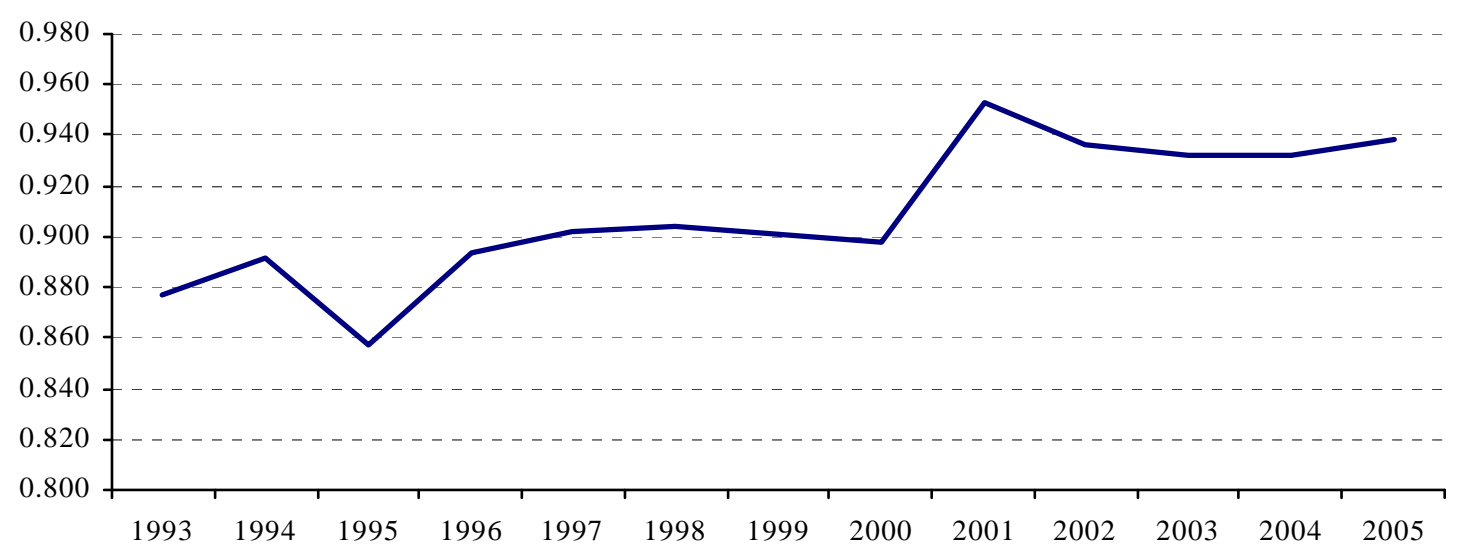

B) Allocative efficiency trend

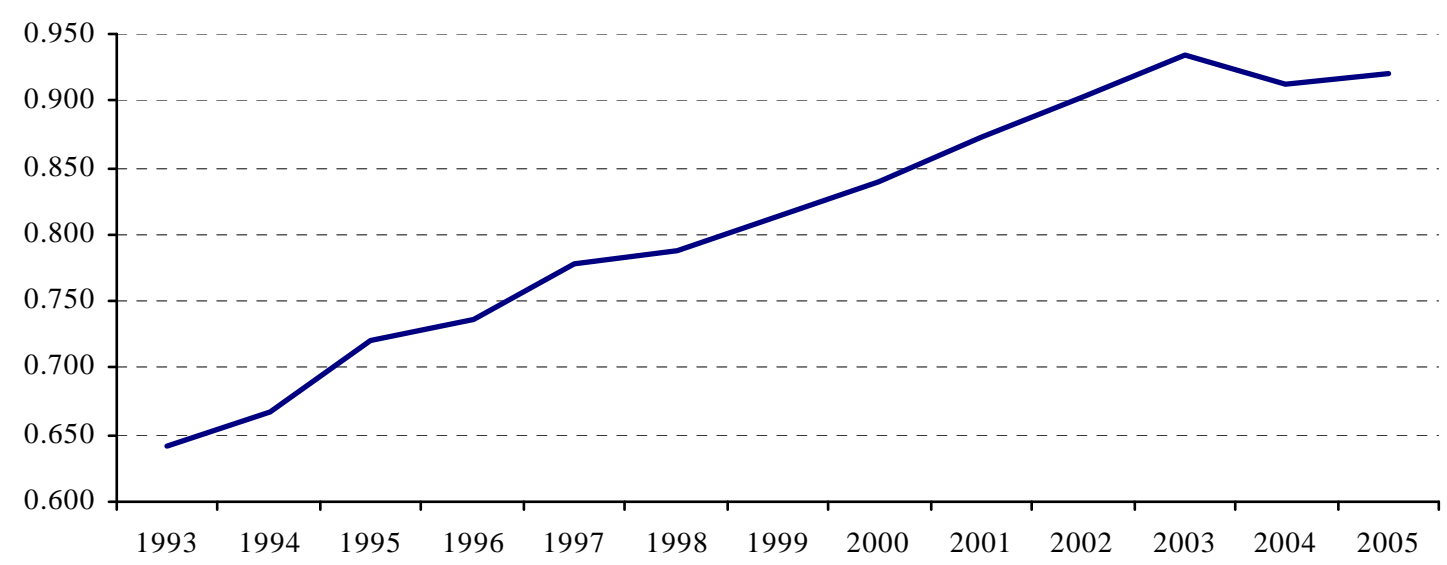

Figure 2: DEA technical and allocative efficiency trends

Technical and allocative efficiency trends are depicted in Figure 2. Technical efficiency initially falls in an interval between 0.88 and 0.90 and then shows an upwards shift to around 0.94 after 1999. The average efficiency value before 1999 price review is 0.891 , while its average value during the 1999 price setting period is 0.940 . Thus, it seems that the 1999 price review stimulated a technical efficiency progress of around 5\%, whereas 1994 price review had no effect. Allocative efficiency, by contrast, shows a continuously increasing trend which does not seem to depend on regulatory interventions. 
This upwards trend raised allocative efficiency from 0.650 to more than 0.900 , indicating that the firms chiefly addressed their efforts to reducing economic inefficiency through a better input mix settlement.

The input-specific allocative distortion measures, calculated as difference between technical efficient input levels and corresponding cost-minimizing values, are depicted in Figure 3.

A) EMPL allocative distortion trend

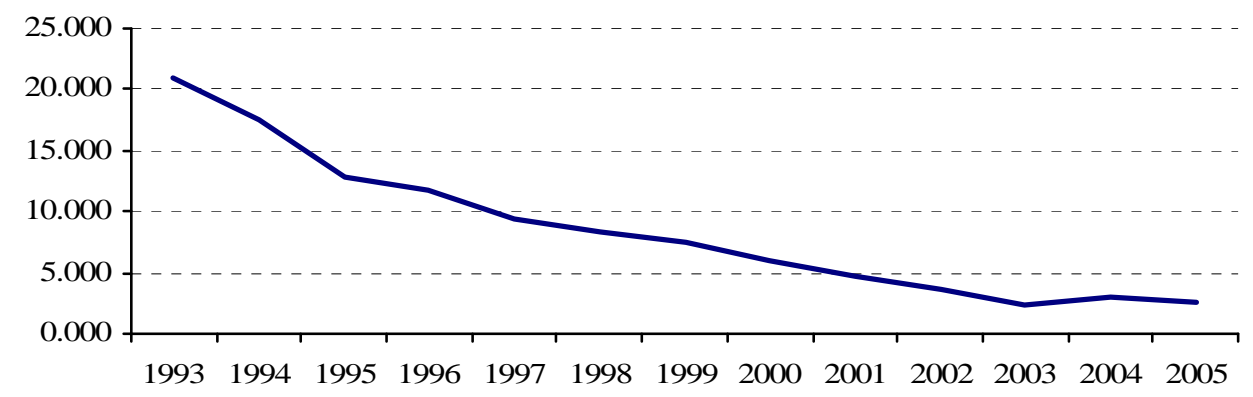

B) OTHEX allocative distortion trend

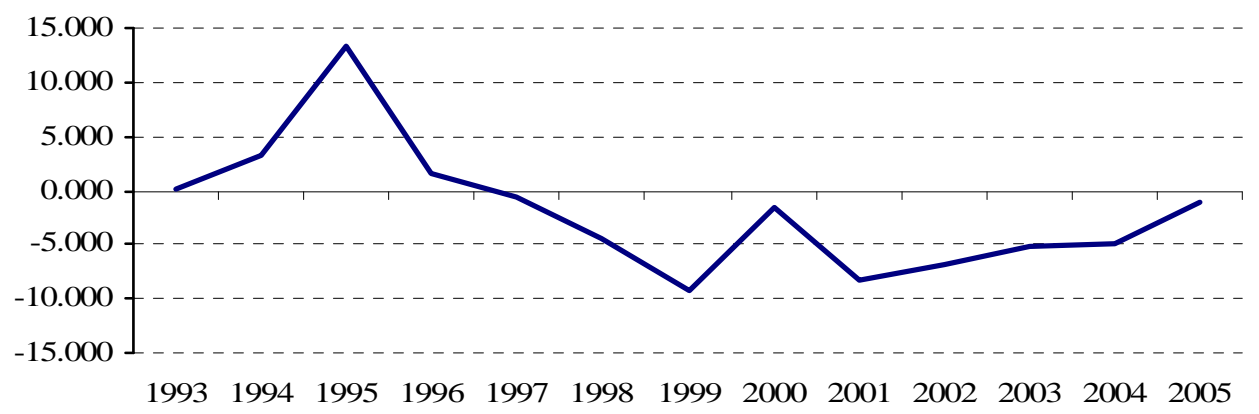

C) CAPEX allocative distortion trend

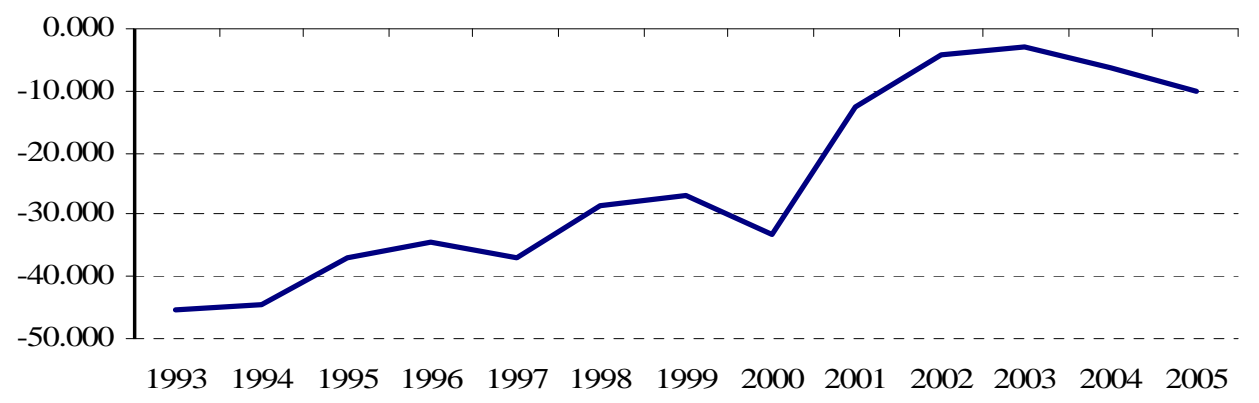

Figure 3: Average input allocative distortion trends

The graphs allow comments in terms of both sign and trend of the distortion. Figure 3 shows an initial systematic over-utilization of labor and under-utilization of capital (respectively of more than $80 \%$ and $-25 \%$ compared with the technically optimum value), which tend to gradually cancel out during time. This result is consistent with previous evidence in Saal and Parker $(2000,2001)$. One explanation is that this could stem from the 
previous public nature of these firms. Pint (1991) and Boycko et al (1996) ascribe over employment to public firms' social - rather than cost-minimizing - objectives.

As regards capital, an explanation for under-capitalization before privatization is capital rationing. Indeed, one important reason for privatization was to remove from Government the liability of funding the water industry's investment program. The extensive capital investments required after privatization in order to expand or renew the network, as well as to meet higher quality and environmental standards enhanced the capital stock and reduced allocative inefficiency. The capital allocative distortion trend seems to have been affected by the 1999 price review. However, this could also be due to the reduction in the cost of capital. Anyway, as distinct from Saal and Parker (2001), we do not find evidence of over-capitalization.

As regards the OTHEX variable, the results point out an initial over-utilization followed by a negative allocative distortion. This could be due to the flexibility of this input. Another reason could be the rapid reduction in energy prices experienced in the same period. This could have increased the cost-minimizing level of energy. However, as energy consumption is quite rigidly linked to the capital endowment, it seems difficult to interpret the rising distortion as allocative inefficiency.

\subsection{Input-specific environmental and regulatory impact}

In this section, we will discuss the impact of the environmental and regulatory factors on input-specific efficiency performance.

The results from the second stage input-based SFA equations with respect to technical inefficiency are presented in Table 3.

\begin{tabular}{|l|l|l|l|l|l|l|l|l|l|}
\hline & \multicolumn{3}{l}{ EMPL } & \multicolumn{3}{l|}{ OTHEX } & \multicolumn{3}{l|}{ CAPEX } \\
\hline & Parameter & $t$-ratio & & Parameter & $t$-ratio & & Parameter & $t$-ratio & \\
\hline SOURCE & -7.249 & $(-2.936)$ & $* * *$ & -61.916 & $(-3.457)$ & $* * *$ & -84.907 & $(-5.633)$ & $* * *$ \\
\hline WLOSS & 18.271 & $(3.346)$ & $* * *$ & 97.948 & $(2.652)$ & $* * *$ & 29.288 & $(1.039)$ & \\
\hline WDENS & -37.978 & $(-2.813)$ & $* * *$ & -222.181 & $(-2.338)$ & $* *$ & -98.553 & $(-0.794)$ & \\
\hline SDENS & 0.292 & $(0.036)$ & & -17.047 & $(-0.333)$ & & -9.366 & $(-0.233)$ & \\
\hline TREFFL & 5.662 & $(0.341)$ & & -5.564 & $(-0.050)$ & & -155.325 & $(-1.601)$ & $*$ \\
\hline REG94 & -0.645 & $(-0.900)$ & & -2.844 & $(-0.622)$ & & -4.124 & $(-1.190)$ & \\
\hline REG99 & -1.893 & $(-2.575)$ & $* * *$ & -13.362 & $(-2.857)$ & $* * *$ & -10.427 & $(-2.848)$ & $* * *$ \\
\hline TIME & 0.588 & $(3.436)$ & $* * *$ & 3.815 & $(3.385)$ & $* * *$ & 1.886 & $(1.962)$ & $* *$ \\
\hline$\gamma$ & 0.855 & $(11.080)$ & $* * *$ & 0.889 & $(14.341$ & $* * *$ & 0.957 & $(41.718)$ & $* * *$ \\
\hline$\eta$ & 0.071 & $(5.619)$ & $* * *$ & 0.064 & $(4.963)$ & $* * *$ & 0.034 & $(3.322)$ & $* * *$ \\
\hline Likelihood & -284.856 & & & -526.279 & & & -497.353 & & \\
\hline
\end{tabular}

Table 3: Environmental and regulatory impact on input-specific technical inefficiency

Note: Estimates marked with $\left({ }^{* *}\right)$ are statistically significant at $1 \%$ level; estimates marked with $\left({ }^{* *}\right)$ are significant at $5 \%$ level; estimates marked with $(*)$ are significant at $10 \%$ level

The SOURCE variable is always associated with negative and significant parameters, indicating that a greater proportion of underground water has beneficial effects on the 
input requirements. The $W L O S S$ variable shows a positive and significant parameter with respect to EMPL and OTHEX equations, so indicating that more critical operational characteristics of the quasi-fixed input (that is, the network) produce higher inefficiency in the use of variable inputs. The negative and significant impact of the WDENS variable on $E M P L$ and OTHEX reflects a favorable condition associated to a higher water network density. The SDENS does not exhibit the same property even though the parameter is negative in two cases (for similar results, see Tupper and Resende (2004)). The TREFFL variable is generally associated with statistically insignificant parameters. Only the negative impact on $C A P E X$ is marginally significant (at $10 \%$ level), thus indicating that a higher proportion of industrial effluent in total waste water, though it imposes - ceteris paribus - higher levels of capital, is associated to better performance in the use of this input.

Turning to the regulatory dummies, it should be note that REG94 has generally the expected (negative) sign but it is not significant, whereas $R E G 99$ is negative and always strongly significant. This result could be explained by invoking the change in the regulatory policy that took place in 1999. Finally, TIME is significant but with a positive sign. This evidence does not allow us to accept the hypothesis of positive technical progress (see Ashton 2000b) but rather supports a picture of more intensive input requirements associated with an infrastructure and non-infrastructure investment process designed to provide higher quality services to customers.

\begin{tabular}{|l|l|l|l|}
\hline & EMPL & OTHEX & CAPEX \\
\hline 1993 & 1.280 & 1.380 & 1.496 \\
\hline 1994 & 1.267 & 1.335 & 1.417 \\
\hline 1995 & 1.287 & 1.334 & 1.408 \\
\hline 1996 & 1.276 & 1.314 & 1.385 \\
\hline 1997 & 1.277 & 1.289 & 1.376 \\
\hline 1998 & 1.262 & 1.284 & 1.336 \\
\hline 1999 & 1.272 & 1.268 & 1.333 \\
\hline 2000 & 1.263 & 1.236 & 1.334 \\
\hline 2001 & 1.239 & 1.234 & 1.291 \\
\hline 2002 & 1.221 & 1.214 & 1.277 \\
\hline 2003 & 1.209 & 1.197 & 1.258 \\
\hline 2004 & 1.188 & 1.186 & 1.255 \\
\hline 2005 & 1.177 & 1.171 & 1.250 \\
\hline Overall reduction & $-10.3 \%$ & $-20.9 \%$ & $-24.6 \%$ \\
\hline
\end{tabular}

Table 4: Input-specific technical overuse coefficients

Note: The yearly average values are calculated as $\left(U_{i t}+T E \times x_{i t}\right) / T E \times x_{i t}$ (where $U_{i t}$ is the input-specific technical inefficiency term, derived from eq. (4)) 
The $\gamma$ parameters are close to 1 and always statistically significant at $1 \%{ }^{29}$ This indicates that the variability of the one-sided inefficiency term $(u)$ dominates the variability due to noise $(v)$. In other words, once exogenous operational characteristics have been purged and all firms are considered as operating in a common virtual context without regulatory and time effects, they still manage their inputs differently. This difference reflects their intrinsic inefficiency.

The $\eta$ parameters are in all cases positive and statistically significant at $1 \%$. This means that the trend of the input-specific technical inefficiency is negative, which implies that managers' ability to reduce overuse of inputs improved over time.

The percentages of overuse with respect to the technically optimal best practice are presented, input-by-input, in Table 4.

The greatest reduction concerns CAPEX (-24.6\%), which starts from the most inefficient position (49.6\% inefficiency in financial year 1992-93), whereas the lowest one belongs to EMPL factor (-10.3\%) which starts from a lesser $28.0 \%$ coefficient of over-use.

The estimates relative to the allocative distortions are presented in Table 5. Here, the regulatory dummies do not play a significant role, even though they have the expected sign. This lack of significance could be explained by arguing that the convergence to the cost-minimizing input mix was a gradual process driven by managers' changing perception of the new economic context. The $\eta$ parameters are positive and highly significant, indicating that this convergence could be attributed to managers' increasing skill in organizing resources. This process focused particularly on labor, as is shown by the magnitude of the corresponding $\eta$ parameter (0.373).

The TIME variable is negative but not significant. It is interesting to note that TIME works in opposite direction for technical and allocative input-specific inefficiency measures. This result seems to shed some light on the role of the technical progress/regress which has an ambiguous impact in the literature (see Ashton 2000b and Saal and Parker, 2001).

\begin{tabular}{|l|l|l|l|l|l|l|l|l|l|}
\hline & \multicolumn{3}{|l}{ EMPL } & \multicolumn{3}{l}{ OTHEX } & \multicolumn{3}{l|}{ CAPEX } \\
\hline & Parameter & $t$-ratio & & Parameter & $t$-ratio & & Parameter & $t$-ratio & \\
\hline REG94 & -2.469 & $(1.390)$ & & -1.244 & $(-0.297)$ & & 5.001 & $(0.770)$ & \\
\hline REG99 & -2.023 & $(-1.102)$ & & -2.419 & $(-0.530)$ & & -1.314 & $(-0.190)$ & \\
\hline TIME & -0.078 & $(-0.235)$ & & -0.204 & $(-0.242)$ & & -1.647 & $(-1.230)$ & \\
\hline$\gamma$ & 0.006 & $(1.269)$ & $* * *$ & 0.353 & $(2.019)$ & $* * *$ & 0.518 & $(3.121)$ & $* * *$ \\
\hline$\eta$ & 0.373 & $(13.487)$ & $* * *$ & 0.071 & $(2.295)$ & $* *$ & 0.094 & $(4.054)$ & $* * *$ \\
\hline Likelihood & -400.642 & & & -513.308 & & & -571.629 & & \\
\hline
\end{tabular}

Table 5: Regulatory impact on input-specific allocative distortion

Note: Estimates marked with $\left({ }^{* *}\right)$ are statistically significant at $1 \%$ level; estimates marked with $\left({ }^{* *}\right)$ are significant at $5 \%$ level

Input-by-input measures of allocative managerial inefficiency have been derived by computing the coefficients of distortion depicted in Table 6. As we used the absolute value

\footnotetext{
${ }^{29}$ The one-sided generalised likelihood-ratio test of $\mathrm{H}_{0}: \gamma=0$ always exceeds the $1 \%$ critical value of 5.412 . Hence, the traditional average response function is not a correct representation of the data (Coelli $e t a l$, 2005).
} 
of the overall input slacks into the equations (5), these allocative inefficiency measures should be interpreted as deviations from cost-minimizing input levels, without distinction upon the direction of the distortion. ${ }^{30}$

As already noted, the labor factor shows a powerful convergence (-71.3\%). Starting from a position of over-utilization, the reorganization process led de facto the factor to its allocatively optimal level. The correction for OTHEX has been equal to $-4.4 \%$, while a percentage of $-16.0 \%$ is observed for $C A P E X$, which started from a position of sub-optimal utilization. These findings also suggest that the reorganization process could have taken the form of capital for labor substitution, consistently with the findings by Saal and Parker (2001).

\begin{tabular}{|l|l|l|l|}
\hline & EMPL & OTHEX & CAPEX \\
\hline 1993 & 1.721 & 1.079 & 1.247 \\
\hline 1994 & 1.480 & 1.071 & 1.218 \\
\hline 1995 & 1.343 & 1.069 & 1.204 \\
\hline 1996 & 1.230 & 1.064 & 1.182 \\
\hline 1997 & 1.159 & 1.059 & 1.163 \\
\hline 1998 & 1.111 & 1.056 & 1.149 \\
\hline 1999 & 1.076 & 1.052 & 1.135 \\
\hline 2000 & 1.052 & 1.049 & 1.123 \\
\hline 2001 & 1.036 & 1.045 & 1.111 \\
\hline 2002 & 1.024 & 1.044 & 1.112 \\
\hline 2003 & 1.016 & 1.041 & 1.100 \\
\hline 2004 & 1.011 & 1.038 & 1.097 \\
\hline 2005 & 1.008 & 1.035 & 1.087 \\
\hline Overall reduction & $-71.3 \%$ & $-4.4 \%$ & $-16.0 \%$ \\
\hline
\end{tabular}

Table 6: Input-specific allocative convergence coefficients

Note: The yearly average values are calculated as $\left(U_{i t}+x_{i t}{ }^{*}\right) / x_{i t}{ }^{*}$ (where $U_{i t}$ is the input-specific allocative distortion term, derived from eq. (5))

\section{Conclusions and policy remarks}

In this study, we extend the previous analysis on the regulatory policy impact in the context of the England and Wales water and sewerage industry to cover a longer period. As far as the 1994 price review is concerned, the previous empirical evidence did not provide strong support of a positive effect of regulatory interventions on cost efficiency. However, the 1999 price control showed a change in the regulatory policy, which for the first time imposed a real price reduction, which may be expected to lead to a change in firm's behavior.

\footnotetext{
${ }^{30}$ It is worth noting that $E M P L$ and $C A P E X$ are characterised respectively, by over and under-utilisation for most of the observations. Only OTHEX shows alternating positive and negative signs in the measure of allocative distortion.
} 
We analyze the impact of regulation on both technical and allocative efficiency components, using a DEA-based two-stage method, derived from Fried et al (2002), which allows taking into account environmental effects, as well as noise. This permitted us to circumvent the major drawbacks inherent DEA methodology and to build up input-specific efficiency measures.

The results can be summarized as follows:

- the 1994 price review period maintained the previous record of limited productivity improvement, whereas the 1999 review period showed significant improvements as far as technical efficiency is concerned;

- the overall allocative efficiency measure, as well as the input-specific allocative distortions improved continuously during the observed period. The firms at first exhibited over-utilization of labor and under-utilization of capital but these distortions reduce gradually over time;

- the trend of pure managerial efficiency shows evidence of a significant improvement in managerial capabilities during the observed period, both in technical and allocative terms.

In light of these results and noting that our dataset does not allow any direct judgment about privatization, some conclusions can be drawn. The regulatory environment set after privatization seems to have improved allocative efficiency through the elimination of the initial input distortions. Thus, previous evidence of labour-saving capital-augmenting technological change is confirmed. The introduction of indirect competition through a yardstick competition system may have induced the firms to be more efficient in choosing cost-minimizing inputs combination. Furthermore, the results seem consistent with those theories that predict an overuse of labor by the publicly-owned firms, whether through a managerial preference for over-employment or difficulties over access to capital markets. The removal of these constraints could have induced this input substitution.

What explains the time patterns of improvements in technical efficiency? More particularly, do the results suggest - in a broader regulatory perspective - that tougher targets elicit greater efforts to eliminate inefficiency? We noted at the outset that, absent problems associated with the ratchet effect, investors derive broadly the same benefits from cost reduction within a price control period however demanding or lax is the implicit productivity target embodied in the cap. Firms may, however, respond differently to tough targets for a number of reasons, including the following: tough targets may more closely align the interests of managers with those of shareholders and prevent managers from enjoying a relatively quiet life; secondly, suppliers of debt finance may spring into action if their returns were threatened. Our sample does not enable us to discriminate among these or other explanations but our results raise questions for regulators and others over how price caps work in practice. We will return to some of them in a later paper which will also examine the much laxer 2004 price control review.

Finally, what it seems of great interest for regulators is that once operational environment and economic (regulatory) effects have been eliminated, pure managerial efficiency could be elicited, giving a more precise assessment of the change of managers' incentives over time. In terms of both technical and allocative efficiency, there is evidence of improving managerial performance. This may be seen as consequence of the change in 
ownership, as well as of the system of performance assessment set up by the regulator after privatization.

\section{$9 \quad$ References}

Anwandter, L. and T. Ozuna (2002) "Can Public Sector Reforms Improve the Efficiency of Public Water Utilities?” Environment and Development Economics, 7: 687-700.

Armstrong, M. and D. Sappington (2007) "Recent Developments in the Theory of Regulation,” in M. Armstrong and R. Porter (ed.), Handbook of Industrial Organisation, (Vol. III), North Holland: Amsterdam, 1557-1700.

Ashton, J.K. (2000a) "Cost Efficiency in the UK Water and Sewerage Industry," Applied Economics Letters, 7: 455-458.

Ashton, J., K. (2000b) "Total Factor Productivity Growth and Technical Change in the Water and Sewerage Industry,” The Service Industries Journal, 20: 121-130

Aubert, C. and A. Reynaud (2005) "The Impact of Regulation on Cost Efficiency: An Empirical Analysis of Wisconsin Water Utilities," Journal of Productivity Analysis, 23: 383-409.

Banker, R.D., A. Charnes and W.W. Cooper (1984) "Some Models for Estimating Technical and Scale Inefficiencies in Data Envelopment Analysis," Management Science, 30: 1078-1092.

Banker, R.D. and R.C. Morey (1986) "Efficiency Analysis for Exogenously Fixed Inputs and Outputs,” Operations Research, 34: 513-521.

Battese, G.E. and T.J. Coelli (1992) "Frontier Production Function, Technical Efficiency and Panel Data: With Application to Paddy Farmers in India," Journal of Productivity Analysis, 3: 153-169.

Bhattacharrya, A., T.R Harris., R. Narayanan and K. Raffiee (1995a) "Specification and Estimation of the Effect of Ownership on the Economic Efficiency of the Water Utilities," Regional Science and Urban Economics, 25: 759-784.

Bhattacharrya, A., T.R. Harris, R. Narayanan and K. Raffiee (1995b) "Allocative Efficiency of Rural Nevada Water Systems: A Hedonic Shadow Cost Function Approach,” Journal of Regional Science, 35: 485-501.

Bhattacharrya, A., E. Parker and K. Raffiee (1994) "An Examination of the Effect of Ownership on the Relative Efficiency of Public and Private Water Utilities," Land Economics, 70: 197-209. 
Bhattacharyya, A., C.A.K. Lovell and P. Sahay (1997) "The Impact of Liberalization on the Productive Efficiency of Indian Commercial Banks,” European Journal of Operational Research, 98: 332-347.

Bottasso, A. and M. Conti (2003) "Cost Inefficiency in the English and Welsh Water Industry: An Heteroskedastic Stochastic Cost Frontier Approach,” Economics Discussion Papers 573, University of Essex (UK), Department of Economics.

Boycko, M., A. Shleifer and R.W. Vishny (1996) “A Theory of Privatisation,” Economic Journal, 106: 309-319.

Charnes, A., W.W. Cooper and E. Rhodes (1978) "Measuring the Efficiency of Decision Making Units,” European Journal of Operational Research, 2: 429-444.

Charnes, A., W.W. Cooper and E. Rhodes (1981) "Evaluating Program and Managerial Efficiency: An Application of Data Envelopment Analysis to Program Follow Through," Management Science, 27: 668-697.

Coelli, T.J., D.S. Prasada Rao, C.J. O’Donnell and G.E. Battese (2005) An Introduction to Efficiency and Productivity Analysis. Springer: New York.

Coelli, T.J., S. Rahman and C. Thirtle (2002) "Technical, Allocative, Cost and Scale Efficiencies in Bangladesh Rice Cultivation: A Non-parametric Approach,” Journal of Agricultural Economics, 53: 607-626.

Coelli, T.J. and S. Walding (2006) "Performance Measurement in the Australian Water Supply Industry: A Preliminary Analysis," in T.J Coelli and D. Lawrence (ed.), Performance Measurement and Regulation of Network Utilities, Edward Elgar Publishing: Cheltenham, 29-61.

Cubbin, J. and G. Tzanidakis (1998) "Regression Versus Data Envelopment Analysis for Efficiency Measurement: An Application to the England and Wales Regulated Water Industry," Utilities Policy, 7: 75-85.

Fabbri, P. and G. Fraquelli (2000) "Cost and Structure of Technology in Italian Water Industry," Empirica, 27: 65-82.

Farrell, M.J. (1957) “The Measurement of Productive Efficiency," Journal of the Royal Statistical Society, Series A, 120: 253-290.

Feigenbaum, S. and R. Teeples (1983) "Public Versus Private Water Delivery: A Hedonic Cost Approach,” The Review of Economics and Statistics, 65: 672-678.

Ferrier, G.D. and C.A.K. Lovell (1990) "Measuring Cost Efficiency in Banking: Econometric and Linear Programming Evidence,” Journal of Econometrics, 46: 229-245.

Fried, H.O., C.A.K. Lovell, S.S. Schmidt and S. Yaisawarng (2002) “Accounting for Environmental Effects and Statistical Noise in Data Envelopment Analysis," Journal of Productivity Analysis, 17: 157-174. 
Fried, H.O., S.S. Schmidt and S. Yaisawarng (1999) "Incorporating the Operating Environment into a Nonparametric Measure of Technical Efficiency," Journal of Productivity Analysis, 12: 249-267.

Garcia, S. and A. Thomas (2001) "The Structure of Municipal Water Supply Costs: Application to a Panel of French Local Communities," Journal of Productivity Analysis, 16: 5-29.

Hunt, L.C. and E.L. Lynk (1995) "Privatisation and Efficiency in the UK Water Industry: An Empirical Analysis,” Oxford Bulletin of Economics and Statistics, 57: 371-388.

Kumbhakar, S.C. (1992) “Allocative Distortions, Technical Progress, and Input Demand in U.S. Airlines: 1970-1984,” International Economic Review, 33: 723-737.

Kumbhakar, S.C. and S. Sarkar (2003) "Deregulation, Ownership, and Productivity Growth in the Banking Industry: Evidence from India," Journal of Money, Credit and Banking, 35: 403-424.

Lambert, D.K., D. Dichev and K. Raffiee (1993) "Ownership and Sources of Inefficiency in the Provision of Water Services,” Water Resources Research, 29: 1573-1578.

Maietta, O.W. (2000) "The Decomposition of Cost Inefficiency into Technical and Allocative Components with Panel Data of Italian Dairy Farms,” European Review of Agricultural Economics, 27: 473-495.

McCarty, T.A. and S. Yaisawarng (1993) "Technical Efficiency in New Jersey School Districts," in H.O. Fried, C.A.K. Lovell and S.S. Schmidt (ed.), The Measurement of Productive Efficiency: Techniques and Applications, Oxford University Press: New York, 271-287.

Mizutani, F. and T. Urakami (2001) "Identifying Network Density and Scale Economies for Japanese Water Supply Organisations,” Papers in Regional Science, 80: 211-230.

Morrison Paul, C.J. (1999) Cost Structure and the Measurement of Economic Performance, Kluwer Academic Publishers: Boston/Dordrecht/London.

The Office of Water Services (OFWAT) (1994) "Future Charges for Water and Sewerage Services: The Outcome of the Periodic Review", available at http://www.ofwat.gov.uk/aptrix/ofwat/publish.nsf/Content/pubshome

The Office of Water Services (OFWAT) (2004) "Investigation into Evidence for Economies of Scale in the Water and Sewerage Industry in England and Wales”, Report commissioned from Stone \& Webster Consultants, available at http://www.ofwat.gov.uk/aptrix/ofwat/publish.nsf/Content/pubshome

Parker, E. (1995) "Shadow Factor Price Convergence and the Response of Chinese StateOwned Construction Enterprises to Reform,” Journal of Comparative Economics, 21: 5481. 
Pint, E. (1991) "Nationalisation versus Regulation of Monopolies: The Effects of Ownership on Efficiency,” Journal of Public Economics, 44: 131-164.

Saal, D. and D. Parker (2000) "The Impact of Privatization and Regulation on the Water and Sewerage Industry in England and Wales: A Translog Cost Function Model," Managerial and Decision Economics, 21: 253-268.

Saal, D. and D. Parker (2001) "Productivity and Price Performance in the Privatized Water and Sewerage Companies of England and Wales," Journal of Regulatory Economics, 20: 61-90.

Saal, D. and D. Parker (2004) "The Comparative Impact of Privatisation and Regulation on Productivity Growth in the English and Welsh Water and Sewerage Industry: 1985-99," International Journal of Regulation and Governance, 4: 139-170.

Saal, D., D. Parker and T. Weyman-Jones (2007) "Determining the Contribution of Technical Change, Efficiency Change and Scale Change to Productivity Growth in the Privatized English and Welsh Water and Sewerage Industry: 1985-2000," Journal of Productivity Analysis, 28:127-139.

Saal, D. and S. Reid (2004) "Estimating Opex Productivity Growth in English and Welsh Water and Sewerage Companies: 1993-2003,” Working Paper RP0434, Aston Business School, Aston University (UK).

Stewart, M. (1993) "Modelling Water Costs 1992-93: Further Research into the Impact of Operating Conditions on Company Costs," Research Paper, The Office of Water Services (OFWAT), Birmingham (UK)

Stewart, M. (1994) "Modelling Sewage Treatment Costs 1992-93: Research into the Impact of Operating Conditions on the Costs of the Sewerage Network,” Research Paper, The Office of Water Services (OFWAT), Birmingham (UK).

Thanassoulis, E. (2000a) "The Use of Data Envelopment Analysis in the Regulation of UK Water Utilities: Water Distribution,” European Journal of Operational Research, 126: 436-453.

Thanassoulis, E. (2000b) "DEA and Its Use in the Regulation of Water Companies," European Journal of Operational Research, 127: 1-13.

Thanassoulis, E. (2001) Introduction to the Theory and Application of Data Envelopment Analysis. Kluwer Academic Publishers: Boston/Dordrecht/London.

Torres, M. and C.J. Morrison Paul (2006) "Driving Forces for Consolidation or Fragmentation of the US Water Utility Industry: A Cost Function Approach with Endogenous Output,” Journal of Urban Economics, 59: 104-120.

Tupper, H.C. and M. Resende (2004) "Efficiency and Regulatory Issues in the Brazilian Water and Sewerage Sector: An Empirical Study,” Utilities Policy, 12: 29-40. 
Uri, N.D. (2003) “The Adoption of Incentive Regulation and its Effect on Technical Efficiency in Telecommunication in the United States," International Journal of Production Economics, 86: 21-34.

Weyman-Jones, T., J. Bouchina, C. Godinho, C. Feteira Inacio, P. Martins and J. Latore (2006) "Efficiency Analysis for Incentive Regulation," in T.J Coelli and D. Lawrence (ed.), Performance Measurement and Regulation of Network Utilities, Edward Elgar Publishing: Cheltenham, 329-363. 